\title{
The anterior temporal artery: an underutilized but robust donor for revascularization of the distal middle cerebral artery
}

\author{
Ali Tayebi Meybodi, MD, Michael T. Lawton, MD, Dylan Griswold, Pooneh Mokhtari, PhD, \\ Andre Payman, and Arnau Benet, MD
}

Skull Base and Cerebrovascular Laboratory, Department of Neurosurgery, University of California, San Francisco, California

OBJECTIVE The anterior temporal artery (ATA) supplies an area of the brain that, if sacrificed, does not cause a noticeable loss of function. Therefore, the ATA may be used as a donor in intracranial-intracranial (IC-IC) bypass procedures. The capacities of the ATA as a donor have not been studied previously. In this study, the authors assessed the feasibility of using the ATA as a donor for revascularization of different segments of the distal middle cerebral artery (MCA).

METHODS The ATA was studied in 15 cadaveric specimens ( 8 heads, excluding 1 side). First, the cisternal segment of the artery was untethered from arachnoid adhesions and small branches feeding the anterior temporal lobe and insular cortex, to evaluate its capacity for a side-to-side bypass to insular, opercular, and cortical segments of the MCA. Any branch entering the anterior perforated substance was preserved. Then, the ATA was cut at the opercular-cortical junction and the capacity for an end-to-side bypass was assessed.

RESULTS From a total of 17 ATAs, 4 (23.5\%) arose as an early MCA branch. The anterior insular zone and the frontal parasylvian cortical arteries were the best targets (in terms of mobility and caliber match) for a side-to-side bypass. Most of the insula was accessible for end-to-side bypass, but anterior zones of the insula were more accessible than posterior zones. End-to-side bypass was feasible for most recipient cortical arteries along the opercula, except for posterior temporal and parietal regions. Early ATAs reached significantly farther on the insular MCA recipients than non-early ATAs for both side-to-side and end-to-side bypasses.

CONCLUSIONS The ATA is a robust arterial donor for IC-IC bypass procedures, including side-to-side and end-to-side techniques. The evidence provided in this work supports the use of the ATA as a donor for distal MCA revascularization in well-selected patients.

https://thejns.org/doi/abs/10.3171/2016.8.JNS161225

KEY WORDS intracranial-intracranial bypass; pterional craniotomy; sylvian fissure; aneurysms; vascular disorders

$\mathrm{S}$ URGICAL treatment of complex middle cerebral artery (MCA) aneurysms is challenging because aneurysm obliteration is technically demanding and often requires revascularization of the distal MCA territory. Extracranial (EC)-intracranial (IC) bypass techniques are commonly used for this purpose, ${ }^{14,18,20,22,29,30}$ but IC-IC bypass techniques are gaining attention as they offer matched donor-recipient arterial calibers, spare the patient from multiple incisions, and require fewer suture lines, which may increase bypass patency. ${ }^{2,17,26,31}$ Four main techniques of IC-IC bypass are typically used to treat complex MCA aneurysms: 1) reanastomosis, which involves using the parent artery as the donor; 2) interpositional bypass, which uses a graft vessel between another donor artery and the recipient; 3) in situ anastomosis, which connects 2 parallel arteries that are close to each other; and 4) reimplantation, which connects the recipient artery to the side of the parent artery. ${ }^{31}$ Each of these bypass techniques carries its own requirements and risks, ${ }^{26,31}$ including the risk to the vascular territory of the donor artery during the bypass procedure, which is a disadvantage of all IC-IC bypasses.

The anterior temporal artery (ATA) is an intracranial artery whose occlusion does not cause significant clinical neurological deficit, an uncommon feature of the intracra-

ABBREVIATIONS $\mathrm{AA}=$ angular artery; $\mathrm{AP}=$ anterior parietal; $\mathrm{ATA}=$ anterior temporal artery; $\mathrm{CA}=$ central artery; $\mathrm{EC}=$ extracranial; $\mathrm{IC}=$ intracranial; $\mathrm{MCA}=$ middle cerebral artery; $\mathrm{MT}=$ middle temporal; $\mathrm{OF}=$ orbitofrontal; $\mathrm{PC}=$ precentral; $\mathrm{PF}=$ prefrontal; $\mathrm{PP}=$ posterior parietal; $\mathrm{PT}=$ posterior temporal; $\mathrm{TO}=$ temporooccipital; $\mathrm{TP}=$ temporopolar.

SUBMITTED May 12, 2016. ACCEPTED August 1, 2016.

INCLUDE WHEN CITING Published online November 11, 2016; DOI: 10.3171/2016.8.JNS161225. 
nial arteries. ${ }^{13,15,26,31,32}$ Consequently, the ATA is a potential donor for IC-IC bypasses because its temporary occlusion during the anastomosis does not add any clinically significant ischemia to that already produced by temporary occlusion of the recipient artery. The ATA has not been widely used as an arterial donor in the bypass armamentarium..$^{10,19,34,35}$ In this study, we sought to define the role of the ATA for revascularization of the MCA territory using simulated bypasses in cadavers.

\section{Methods}

Eight cadaveric heads (15 sides examined) were prepared for surgical simulation in the Skull Base and Cerebrovascular Laboratory of the University of California, San Francisco, using our customized formula. ${ }^{5}$ A large pterional craniotomy was completed with the head in the lateral position using a 3-pin head holder (Mizuho). After opening the dura in a curvilinear fashion, the sylvian fissure was widely opened from the distal end to the proximal end to expose the MCA completely. The 12 named cortical branches ( $\mathrm{M}_{4}$ segments) were identified according to the cortical gyral location of the arteries (Fig. 1A). ${ }^{10}$ The arterial tree was drawn from the origin of the MCA to the distal peri-sylvian cortical branches; specifically, the pattern of ATA origin was recorded (early or non-early MCA branch; early branches originate from the MCA prior to its bifurcation). Next, the cisternal segment of the ATA was freed from arachnoid adhesions. Small branches feeding the anterior aspect of the temporal lobe and insular cortex were cut. The perforating branches (if any) to the anterior perforating substance were preserved (Fig. 1B). Two protocols were used to assess the capacity of this artery for bypass using different bypass techniques.

\section{Side-to-Side Bypass}

The artery was mobilized to evaluate the feasibility of completing a side-to-side bypass to the most distant $\mathrm{M}_{2}$, $\mathrm{M}_{3}$, and $\mathrm{M}_{4}$ branches of the MCA. A successful bypass was determined when a tension-free, side-to-side bypass of a length 3 times the diameter of the recipient artery was possible (Fig. 1C). The exact gyral location of the by- pass, the diameter of the recipient artery at the bypass, and the distance from the bypass to the limen insulae were recorded. The bypass feasibility was not tested for the temporopolar (TP) artery as the recipient because it would not have clinical relevance. Distance measurements were performed with a frameless stereotactic navigation system (Stryker) and the diameters were measured with a handheld caliper.

\section{End-to-Side Bypass}

In the next step, the ATA was divided at the $\mathrm{M}_{3-4}$ junction and the possibility of completing an end-to-side bypass was recorded for $\mathrm{M}_{2}, \mathrm{M}_{3}$, and $\mathrm{M}_{4}$ segments of the MCA in the same sequence as for a side-to-side bypass.

\section{Insular Dimensions}

To further clarify the exact location of the bypass points to the insular segments of the MCA, the anatomy of the insula was conceptualized into a tetragon consisting of 2 triangles attached at the central sulcus of the insula. The short and long gyri of the insula were reconstructed by trisecting and bisecting the anterior and posterior segments of the superior limiting sulcus, respectively, and connecting to the limen insulae. The lengths of the sulci between the short gyri and the sulcus between the anterior long gyrus and posterior long gyrus were calculated trigonometrically. The insular surface was classified into 6 different zones (I-VI) to facilitate interpretation of data as follows: Zone I, anterior to and including the anterior limiting sulcus; Zone II, anterior short gyrus including the sulcus between the anterior short gyrus and the middle short gyrus; Zone III, middle short gyrus including the sulcus between the middle short gyrus and the posterior short gyrus; Zone IV, posterior short gyrus including the central insular sulcus; Zone V, anterior long gyrus including the sulcus between the anterior long gyrus and the posterior long gyrus; and Zone VI, posterior long gyrus including the inferior limiting sulcus of the insula. The average location of the bypass point on each insular zone was calculated as $L_{R}=$ $\bar{P} / \bar{L} \times 100$, in which $L_{R}$ is the average location of the bypass point on each insular zone defined as a percentage of the length of that zone, $P$ is the average distance of the bypass
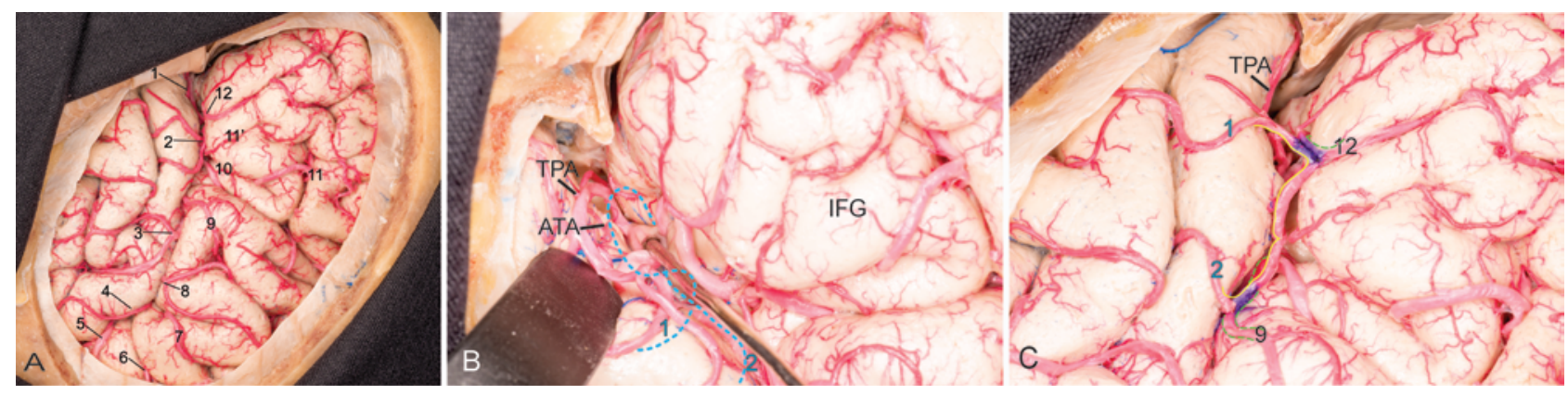

FIG. 1. Cadaveric dissection photographs. A: Twelve cortical branches of the MCA: TP artery (1), ATA (2), MT artery (3), PT artery (4), TO artery (5), AA (6), PP artery (7), AP artery (8), CA (9), PC artery (10), PF artery (11 and 11'), and OF artery (12). B: Opening the sylvian fissure and exposing the ATA (2 branches, numbered 1 and 2 ; dashed line). IFG = inferior frontal gyrus; TPA = TP artery. C: Side-to-side double-barrel bypass from the ATAs (numbered as 1 and 2; contoured with yellow lines) to the OF artery (12) and CA (9) (contoured with dashed green lines). The interrupted green lines outline the course of the recipient arteries. The yellow line outlines the course of donor ATAs. Figure is available in color online only. 
TABLE 1. Origin and course of the ATA in 15 specimens

\begin{tabular}{lrcccccc}
\hline \multirow{2}{*}{ ATA Type } & No. & $\begin{array}{c}\text { Cisternal } \\
\text { Length }(\mathrm{mm})^{*}\end{array}$ & $\begin{array}{c}\text { Proximal } \\
\text { Diameter }(\mathrm{mm})^{*}\end{array}$ & $\begin{array}{c}\text { Distal Diameter } \\
(\mathrm{mm})^{*}\end{array}$ & $\begin{array}{c}\text { Shrinkage } \\
(\mathrm{mm})^{*}\end{array}$ & \multicolumn{2}{c}{ \% Hypoplastic ATA } \\
\cline { 6 - 8 } All & 17 & $36.0 \pm 12.1$ & $1.3 \pm 0.3$ & $1.1 \pm 0.3$ & $0.2 \pm 0.2$ & 18 & 41 \\
\hline Early branching & 4 & $51.4 \pm 5.8$ & $1.4 \pm 0.3$ & $1.3 \pm 0.4$ & $0.1 \pm 0.1$ & & \\
\hline Non-early branch & 13 & $31.3 \pm 9.2$ & $1.2 \pm 0.4$ & $1.0 \pm 0.2$ & $0.2 \pm 0.2$ & \\
\hline
\end{tabular}

* Means \pm standard deviations.

point to the limen insula, and $L$ is the total length of the insular zone.

\section{Results}

\section{Origin and Course of the ATA}

There were 17 ATAs in 15 specimens. Four ATAs $(23.5 \%)$ originated as an early branch from the MCA. There was a significant difference between the cisternal lengths of early ATAs and those from non-early ATAs ( $p<0.05$ ). Table 1 summarizes the characteristics of the ATAs examined in this study.

\section{Side-to-Side Bypass}

$M_{2}$ Segments. The ATA reached 33\%-59\% of the lengths of the insular zones on average for a side-to-side bypass (Table 2, Fig. 2A). Zones I-III accounted for the farthest bypass possible on the insula. Twenty-five percent of the insular segment bypasses reached the $\mathrm{M}_{2-3}$ junction. This was highest for Zones I and VI (53\% and 42\%, respectively). The early ATAs reached an average of $3 \mathrm{~mm}$ farther on the insular surface than non-early ATAs (20.7 \pm 3.1 vs $17.7 \pm 2.6 \mathrm{~mm}$; $\mathrm{p}<0.05)$.

$M_{3}$ Segments. The frontal operculum (containing the orbitofrontal $[\mathrm{OF}]$, prefrontal $[\mathrm{PF}]$, and precentral $[\mathrm{PC}]$ arteries) was most frequently reached by the ATA for a side-to-side bypass. However, the $\mathrm{M}_{3}$ central artery (CA) was not a favorable target for side-to-side bypass ( $24 \%$ reached; Table 3, Fig. 2B). The parietal and occipital opercula were barely reached for a side-to-side bypass. On the other hand, the temporal operculum was often reached for a side-to-side bypass (71\%).

$M_{4}$ Segments. When using the side-to-side technique, the $\mathrm{OF}$ (on the pars orbitalis) and PF (on the posterior part of the inferior frontal gyrus) arteries were the recipients most frequently reached (71\% and 53\%, respectively; Table 4, Fig. 2C). The bypass points on the $\mathrm{M}_{4}$ segments were all located on the parasylvian area. The maximum reach of early ATAs to $\mathrm{M}_{4}$ segments $(28.3 \pm 6.5 \mathrm{~mm})$ was not significantly different from that of non-early ATAs (26.6 $\pm 1.8 \mathrm{~mm} ; \mathrm{p}=0.23$ ).

\section{End-to-Side Bypass}

$M_{2}$ Segments. The ATA reached $56 \%-81 \%$ of the lengths of the insular zones when an end-to-side technique was used (Table 2, Fig. 2D). The $\mathrm{M}_{2-3}$ junction was reached more frequently (average $=86 \%$ ) in Zones I-III, while it was reached least frequently in Zone V (41\%). Except for Zones I and VI, the bypass point reached $\geq 70 \%$ of the length of the respective sulcus, and Zones II-V were most reachable. Early branching ATAs reached farther on the insular surface $(38.4 \pm 6.7 \mathrm{~mm})$ compared with nonearly branching ATAs $(31.6 \pm 3.3 \mathrm{~mm}$; $\mathrm{p}<0.01)$.

$M_{3}$ Segments. The $\mathrm{M}_{3}$ branches on the frontal and temporal lobes had the highest rate of successful bypass (Table 3, Fig. 2E). However, the parietal lobe was not reached for end-to-side bypass in many specimens, and the $\mathrm{M}_{3}$ parietal and angular arteries (AAs) were reached in less than $50 \%$ of the specimens.

$M_{4}$ Segments. The $\mathrm{M}_{4}$ segments of the frontal and temporal lobes were most frequently reached for end-to-side bypass (Table 4, Fig. 2F). Conversely, $\mathrm{M}_{4}$ segments of the parietal and occipital lobes could not be reached in most specimens. The average distance from the bypass point to the limen insulae was $42 \mathrm{~mm}$. The cisternal length of the ATA did not correlate with the maximum distance of the bypass point from the limen insulae (Pearson correlation coefficient $=0.57$ ). Also, maximum reach for cortical re-

TABLE 2. Results of side-to-side and end-to-side bypass to the $M_{2}$ segment

\begin{tabular}{|c|c|c|c|c|c|c|c|c|}
\hline \multirow[b]{2}{*}{$\begin{array}{l}\text { Insular } \\
\text { Zone* }\end{array}$} & \multicolumn{4}{|c|}{ Side-to-Side } & \multicolumn{4}{|c|}{ End-to-Side } \\
\hline & $\begin{array}{c}\text { Relative } \\
\text { Location on } \\
\text { Analogous Zone }\end{array}$ & $\begin{array}{c}\text { Mean } \\
\text { Distance } \pm \\
\text { SD }(\mathrm{mm})\end{array}$ & $\begin{array}{c}\text { Mean } \\
\text { Diameter } \\
\pm \mathrm{SD}(\mathrm{mm})\end{array}$ & $\begin{array}{c}\text { Frequency } \\
\text { of } \mathrm{M}_{2-3} \\
\text { Bypasses (\%) }\end{array}$ & $\begin{array}{c}\text { Relative } \\
\text { Location on } \\
\text { Analogous Zone }\end{array}$ & $\begin{array}{c}\text { Mean } \\
\text { Distance } \pm \\
\text { SD }(\mathrm{mm})\end{array}$ & $\begin{array}{c}\text { Mean } \\
\text { Diameter } \\
\pm \mathrm{SD}(\mathrm{mm})\end{array}$ & $\begin{array}{c}\text { Frequency } \\
\text { of } \mathrm{M}_{2-3} \\
\text { Bypasses (\%) }\end{array}$ \\
\hline I & 0.54 & $16.9 \pm 3.5$ & $1.2 \pm 0.4$ & 53 & 0.63 & $19.6 \pm 6.7$ & $1.1 \pm 0.2$ & 96 \\
\hline II & 0.59 & $16.6 \pm 2.9$ & $1.5 \pm 0.4$ & 20 & 0.81 & $22.6 \pm 6.2$ & $1.5 \pm 0.4$ & 77 \\
\hline III & 0.50 & $14.7 \pm 2.8$ & $1.8 \pm 0.3$ & 0 & 0.81 & $23.9 \pm 5.9$ & $1.6 \pm 0.4$ & 84 \\
\hline IV & 0.36 & $14.4 \pm 2.9$ & $2.0 \pm 0.5$ & 0 & 0.75 & $26.3 \pm 7.8$ & $1.8 \pm 0.3$ & 53 \\
\hline V & 0.33 & $11.0 \pm 2.3$ & $2.4 \pm 0.3$ & 0 & 0.71 & $27.6 \pm 7.3$ & $2.0 \pm 0.6$ & 41 \\
\hline VI & 0.34 & $15.2 \pm 3.7$ & $1.7 \pm 0.4$ & 42 & 0.56 & $25.6 \pm 9.1$ & $1.8 \pm 0.4$ & 70 \\
\hline
\end{tabular}

* See text for description of insular zones. 

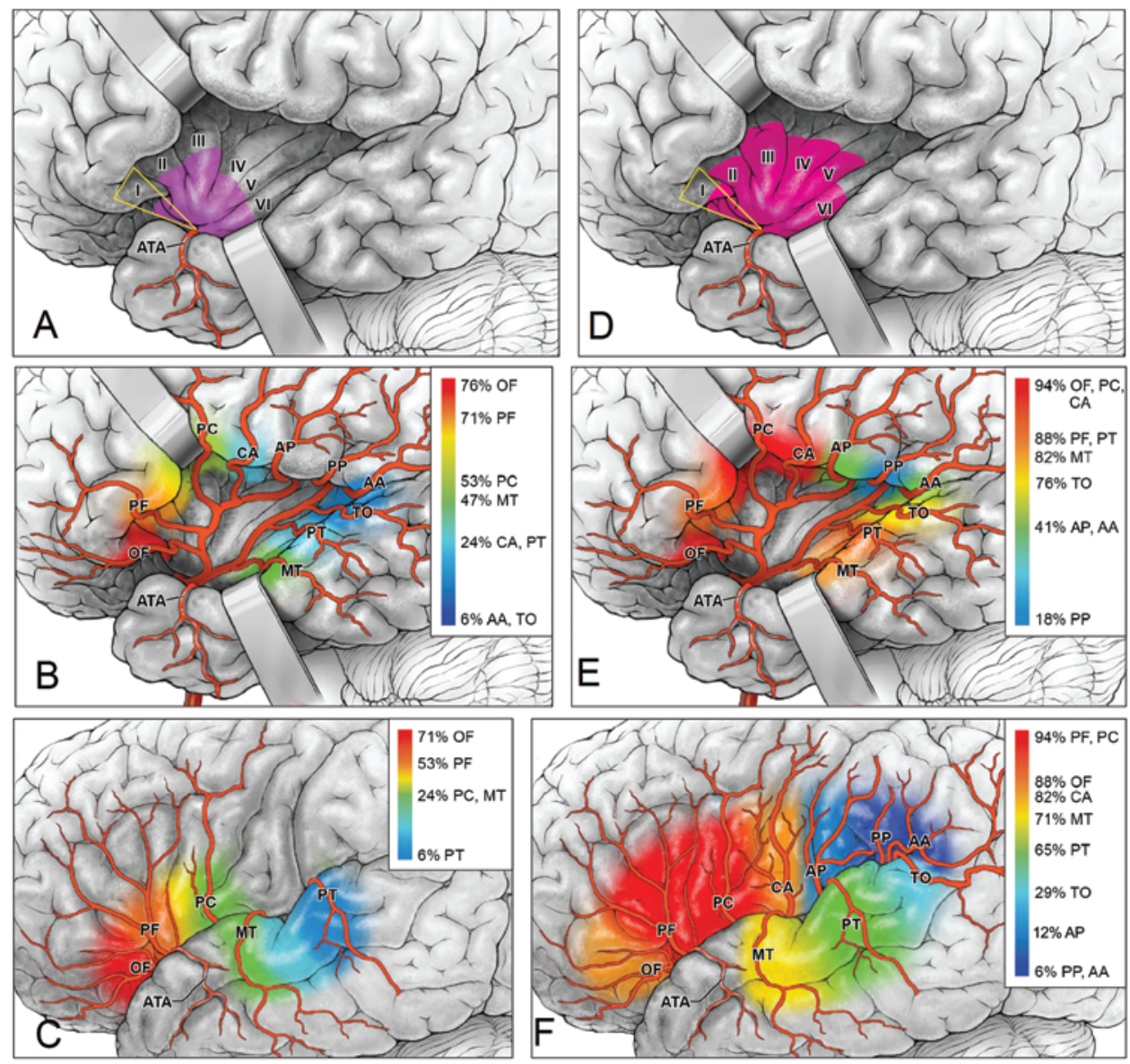

FIG. 2. Illustration showing the average farthest anastomosis for different bypass choices from the ATA to recipient branches of the MCA. A: Average maximum reach of the ATA for a side-to-side bypass to the insular segment of the MCA on different insular zones relative to the average length of each insular zone (see Table 2 for detailed results and text for description of insular zones). Yellow triangle represents Zone I of the insula, which is the area anterior to the anterior short gyrus, including the anterior limiting sulcus. B: Percentage of specimens with a successful side-to-side bypass to the $M_{3}$ segment. C: Percentage of specimens with a successful side-to-side bypass to the $\mathrm{M}_{4}$ segment. D: Average maximum reach of the ATA for an end-to-side bypass to the insular segment of the MCA on different insular zones relative to the average length of each insular zone. Yellow triangle represents Zone I of the insula, which is the area anterior to the anterior short gyrus, including the anterior limiting sulcus. See Table 2 for detailed results. E: Percentage of specimens with a successful end-to-side bypass to the $\mathrm{M}_{3}$ segment. F: Percentage of specimens with a successful end-to-side bypass to the $\mathrm{M}_{4}$ segment. Copyright Arnau Benet. Published with permission. Figure is available in color online only.

cipients was not significantly different between the early and non-early ATAs $(\mathrm{p}=0.20)$.

\section{Case Illustration}

A 24-year-old male patient with a history of infective endocarditis and previous septic embolic strokes of both hemispheres presented with generalized tonic-clonic seizure. Computed tomography of the head showed a large intraparenchymal hemorrhage in the territory of the right MCA (Fig. 3A). Digital subtraction angiography showed a tapering right $\mathrm{M}_{1}$ MCA giving rise to a nonsaccular aneurysm without a discernible neck. The aneurysm dome gave rise to 1 viable efferent branch on the frontal side. The ATA originated as an early branch from the $\mathrm{M}_{1}$ MCA (Fig. 3B and C). After the cisternal segment of the ATA was released, it was mobilized to reach the efferent branch coming off the aneurysm. The aneurysm was trapped and the efferent branch was reimplanted onto the mobilized
ATA (Fig. 3D-G). Postoperative angiography showed obliteration of the aneurysm and bypass patency (Fig. 3H). The patient was discharged without any new neurological deficit.

\section{Discussion}

A feasibility assessment of different bypass techniques using the ATA for revascularization of the distal MCA shows that the ATA can be used as a donor for IC-IC bypass to various recipient arteries on the MCA tree. All previously published studies on the ATA are descriptive and address the anatomical features and variability of the ATA. ${ }^{9,10,34}$ Bederson and Spetzler were among the first to use the ATA to complete a bypass in a case of a pre-bifurcation MCA aneurysm. ${ }^{3}$ Our team has reported the use of the ATA as a donor artery in IC-IC bypass procedures, including an ATA-superior cerebellar artery bypass and 
TABLE 3. Results of side-to-side and end-to-side bypass to the $M_{3}$ segment

\begin{tabular}{|c|c|c|c|c|c|c|}
\hline \multirow[b]{2}{*}{$\begin{array}{l}\text { Recipient } \\
\text { Territory }\end{array}$} & \multicolumn{3}{|c|}{ Side-to-Side } & \multicolumn{3}{|c|}{ End-to-Side } \\
\hline & $\begin{array}{c}\text { Ratio of Successful } \\
\text { Bypass (\%) }\end{array}$ & $\begin{array}{l}\text { Mean Distance } \\
\pm \mathrm{SD}(\mathrm{mm})\end{array}$ & $\begin{array}{l}\text { Mean Diameter } \\
\pm \mathrm{SD}(\mathrm{mm})\end{array}$ & $\begin{array}{c}\text { Ratio of Successful } \\
\text { Bypass (\%) }\end{array}$ & $\begin{array}{l}\text { Mean Distance } \\
\pm \mathrm{SD}(\mathrm{mm})\end{array}$ & $\begin{array}{l}\text { Mean Diameter } \\
\pm \mathrm{SD}(\mathrm{mm})\end{array}$ \\
\hline OF & 76 & $17.6 \pm 4.3$ & $0.98 \pm 0.3$ & 94 & $20.0 \pm 5.4$ & $1.1 \pm 0.5$ \\
\hline PF & 71 & $20.4 \pm 6.4$ & $1.25 \pm 0.3$ & 88 & $25.3 \pm 6.7$ & $1.3 \pm 0.5$ \\
\hline$P C$ & 53 & $18.5 \pm 6.8$ & $1.44 \pm 0.3$ & 94 & $27.7 \pm 6.1$ & $1.6 \pm 0.4$ \\
\hline $\mathrm{CA}$ & 24 & $14.4 \pm 3.6$ & $1.83 \pm 0.3$ & 94 & $31.6 \pm 6.1$ & $1.7 \pm 0.4$ \\
\hline $\mathrm{AP}$ & - & - & - & 41 & $38.4 \pm 7.7$ & $1.5 \pm 0.2$ \\
\hline PP & - & - & - & 18 & $44.9 \pm 9.6$ & $1.6 \pm 0.3$ \\
\hline AA & 6 & $20.0^{*}$ & $1.90^{*}$ & 41 & $35.4 \pm 8.1$ & $1.9 \pm 0.6$ \\
\hline TO & 6 & $20.0^{*}$ & $1.90^{*}$ & 76 & $33.6 \pm 5.8$ & $1.8 \pm 0.5$ \\
\hline MT & 47 & $20.58 \pm 6.9$ & $1.50 \pm 0.3$ & 82 & $21.1 \pm 8.4$ & $1.5 \pm 0.4$ \\
\hline PT & 24 & $22.68 \pm 9.1$ & $1.68 \pm 0.4$ & 88 & $23.8 \pm 9.9$ & $1.7 \pm 0.5$ \\
\hline
\end{tabular}

* Only 1 value, no standard deviation possible.

reimplantation of a frontal MCA trunk onto the ATA.,26,31 However, none of these studies delineate the full potential of the ATA in IC-IC bypass surgery.

\section{Early Branching ATA and Bypass for Proximal MCA Occlusions}

Complex aneurysms and other pathologies affecting the proximal MCA may necessitate occlusion of the MCA trunk as part of their treatment strategy. Early MCA branches (e.g., an early ATA) arising proximal to the site of occlusion can serve as an optimal donor in such cases.

The first early temporal branch usually arises from the main MCA trunk at an average distance of $6-8.5 \mathrm{~mm}$ from the ICA bifurcation. ${ }^{6,33}$ Our results show that in $23.5 \%$ of specimens, the ATA originates as an early branch, having an average diameter of $1.4 \mathrm{~mm}$. The early ATAs were larger than $1 \mathrm{~mm}$ at their origin in all specimens. This large diameter may make them suitable as a low-flow donor. The early branching, cisternal length, and diameter of the ATA can be appreciated preoperatively. However, the actual mobility of the cisternal segment ATA may be difficult or impossible to predict, and therefore the feasibility for bypass to a specific target vessel on the MCA candelabra may prove difficult before surgery.

\section{Constancy of Early ATA Diameter}

Along their cisternal course, early ATAs suffered little shrinkage (mean $0.1 \mathrm{~mm}$ ) in diameter. Thus, the relatively constant diameter of the ATA along its cisternal course makes it a reliable donor for bypass to one of the postbifurcation distal MCA branches.

\section{Maximal Mobility of Early ATA}

An optimal bypass matches the diameters of donor and recipient arteries. ${ }^{26,27}$ Our results show that recipient arteries on Zones I and II match the diameter of the ATAs. This implies that in cases of a proximal MCA occlusion, an early ATA can be optimal for revascularization of the distal MCA, preferably on insular Zones I and II. Moreover, based on our results, an early ATA provides great mobility of its cisternal segment, thus allowing for reaching farther to the recipients on the insular surface (both for side-toside and end-to-side bypasses). This increased mobility may not be needed in cases of proximal MCA occlusion,

TABLE 4. Results of side-to-side and end-to-side bypass to the $M_{4}$ segment

\begin{tabular}{|c|c|c|c|c|c|c|}
\hline \multirow[b]{2}{*}{$\begin{array}{c}\text { Recipient } \\
\text { Territory }\end{array}$} & \multicolumn{3}{|c|}{ Side-to-Side } & \multicolumn{3}{|c|}{ End-to-Side } \\
\hline & $\begin{array}{c}\text { Ratio of Successful } \\
\text { Bypass (\%) }\end{array}$ & $\begin{array}{l}\text { Mean Distance } \\
\pm \mathrm{SD}(\mathrm{mm})\end{array}$ & $\begin{array}{l}\text { Mean Diameter } \\
\pm \mathrm{SD}(\mathrm{mm})\end{array}$ & $\begin{array}{l}\text { Ratio of Successful } \\
\text { Bypass (\%) }\end{array}$ & $\begin{array}{l}\text { Mean Distance } \\
\pm \mathrm{SD}(\mathrm{mm})\end{array}$ & $\begin{array}{l}\text { Mean Diameter } \\
\pm \mathrm{SD}(\mathrm{mm})\end{array}$ \\
\hline OF & 71 & $22.2 \pm 3.8$ & $0.9 \pm 0.2$ & 88 & $31.2 \pm 8.8$ & $0.9 \pm 0.2$ \\
\hline PF & 53 & $25.9 \pm 4.4$ & $1.1 \pm 0.2$ & 94 & $36.8 \pm 6.7$ & $1.1 \pm 0.2$ \\
\hline PC & 24 & $20.7 \pm 3.0$ & $1.2 \pm 0.1$ & 94 & $36.1 \pm 7.9$ & $1.2 \pm 0.3$ \\
\hline $\mathrm{CA}$ & - & - & - & 82 & $36.0 \pm 7.7$ & $1.4 \pm 0.3$ \\
\hline AP & - & - & - & 12 & $44.3 \pm 15.4$ & $1.3 \pm 0.1$ \\
\hline PP & - & - & - & 6 & $65.0^{*}$ & $1.5^{*}$ \\
\hline AA & - & - & - & 6 & $60.0^{*}$ & $1.0^{*}$ \\
\hline TO & - & - & - & 29 & $42.4 \pm 7.3$ & $1.6 \pm 0.4$ \\
\hline MT & 24 & $27.2 \pm 8.3$ & $1.2 \pm 0.2$ & 71 & $29.4 \pm 5.6$ & $1.2 \pm 0.41$ \\
\hline PT & 6 & $26^{*}$ & $1.3^{*}$ & 65 & $35.4 \pm 8.3$ & $1.3 \pm 0.3$ \\
\hline
\end{tabular}

* Only 1 value, no standard deviation possible. 

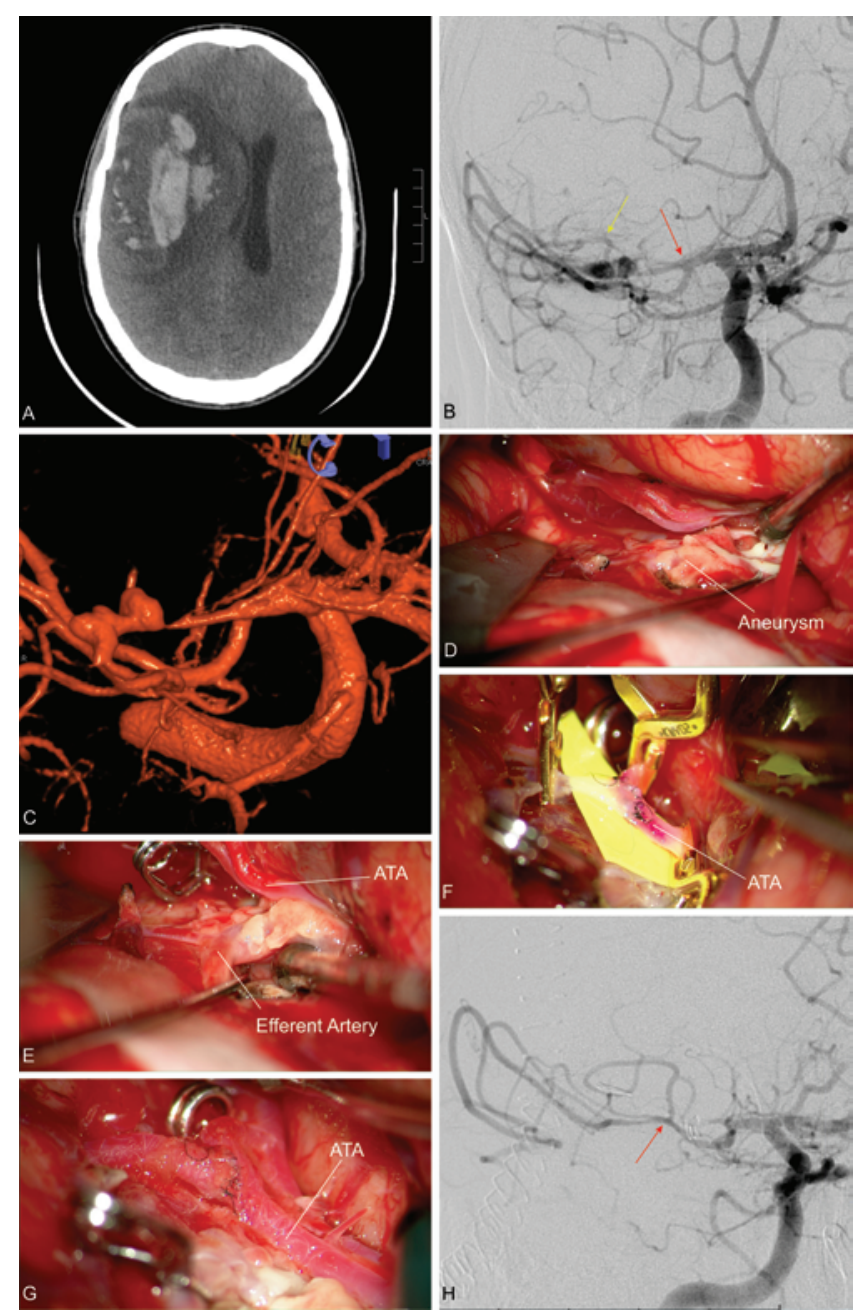

FIG. 3. Illustrative case of mobilization of an early ATA to revascularize an insular branch of the MCA. A-C: Axial CT scan (A), digital subtraction angiogram (B), and 3D digital subtraction angiogram (C). This mycotic aneurysm of the right MCA gave rise to massive intracranial rupture in a 24-year-old man with infective endocarditis and multiple previous septic embolic strokes. An efferent $\mathrm{M}_{2}$ branch originated from the dome of the aneurysm (yellow arrow). The red arrow indicates an early branching ATA. D and E: The aneurysm was exposed via splitting of the sylvian fissure and trapped. $\mathbf{F}$ and $\mathbf{G}$ : The cisternal course of the ATA was released and mobilized to reach the efferent branch coming off the aneurysm. The MCA branch was reimplanted onto the mobilized ATA. H: Postoperative angiogram showing bypass patency. Red arrow indicates the anastomosis. Figure is available in color online only.

where the closest postbifurcation artery would be a desired recipient; however, it is of value when $\mathrm{M}_{2}$ MCA occlusion is required. On the other hand, significantly longer cisternal length of the early ATAs did not show a significant difference from non-early ATAs regarding maximal reach to the cortical MCA. In other words, the early ATA is a more favorable candidate for revascularization in cases of proximal and insular MCA occlusions, but it does not offer much more than non-early ATAs when revascularization of the cortical segment of the MCA is necessary.

\section{Bypass Using the ATA for Distal MCA Occlusions}

Distal MCA aneurysms are rare (1\%-6\% of all cerebral aneurysms). ${ }^{7}, 12,16,28,30,38$ Most distal MCA aneurysms have an unfavorable configuration for clipping. ${ }^{16,30}$ Previous reports do not address the specific gyral location of the distal MCA aneurysms., ${ }^{7,16,23,24}$ Several reports show that distal MCA aneurysms require bypass more often than any other distal aneurysm. ${ }^{23,30}$

\section{ATA for Bypass to Insular MCA}

Our results show that the ATA mobilizes to reach all insular zones $\left(\mathrm{M}_{2}\right.$ segment; Table 2). However, maximal mobility was recorded in the anterior insular zones (Zones I-III) for side-to-side bypasses, and in Zones I-V for endto-side bypasses (Fig. 2A and D). We found that a side-toside bypass would provide the best caliber match in insular Zones I and II while avoiding a cortical infarct in the ATA territory (Table 2). The posterior zones of the insula (IVVI) have arteries with larger diameters, making the ATA a suboptimal candidate for revascularization. Nevertheless, with properly matched donor and recipient diameters, side-to-side bypass is feasible within the proximal third of the posterior insular zones. The reach increases to more than half of the posterior lengths of gyri if an end-to-side bypass is used (Fig. 2A and D).

\section{ATA for Bypass to Opercular and Cortical MCA}

According to our results, the optimal bypass technique (end-to-side vs side-to-side) can be determined by specific locations for bypasses to $\mathrm{M}_{3}$ and $\mathrm{M}_{4}$ segments (Fig. 2B, $\mathrm{C}$, $\mathrm{E}$, and F, and Fig. 4). The parietal and occipital lobe arteries (i.e., anterior parietal [AP] and posterior parietal [PP] arteries, and the AA) were the least accessible at the $\mathrm{M}_{3}$ and $\mathrm{M}_{4}$ level, rendering the ATA suboptimal for bypass on these territories. On the other hand, the $\mathrm{M}_{3}$ and $\mathrm{M}_{4}$ arteries of the anterior frontal region (i.e., the $\mathrm{OF}$ and $\mathrm{PF}$ arteries) were easily reached with both bypass techniques (end-toside having better mobility than side-to-side). However, the best option for the CA, posterior temporal (PT), and MT arteries would be using ATA end-to-side. Also, if the ATA is chosen for bypass to the temporooccipital (TO) artery, end-to-side bypass to the $\mathrm{M}_{3} \mathrm{TO}$ artery may provide the best outcome.

Our results show that the caliber of the ATA, when used side-to-side, matched all reached $\mathrm{M}_{4}$ branches (i.e., frontal and temporal lobe parasylvian $\mathrm{M}_{4}$ branches). However, the $\mathrm{OF}, \mathrm{PF}$, and $\mathrm{PC}$ branches provided the best caliber match to the ATA at the $\mathrm{M}_{3}$ level (Table 3). Therefore, if a sideto-side bypass is needed to the $\mathrm{M}_{3}$ segment of the MCA, the best recipient arteries would be those of the anterior frontal lobe.

\section{Eloquence of ATA Cortical Territory}

The clinical consequences specific to ATA occlusion are not reported in the literature. ${ }^{11,36}$ However, studies on anterior temporal lobectomy for temporal lobe epilepsy generally show that resection of the anterior temporal cortex does not carry risk for major neurological deficits. There is clinical consensus that the resection of $3-4.5 \mathrm{~cm}$ of the anterior of the dominant temporal lobe and $4.5-6 \mathrm{~cm}$ of the nondominant temporal lobe is considered safe. ${ }^{4,8,21,25,37}$ However, extrapolation of such results to ligation of the ATA for end-to-side bypass may 


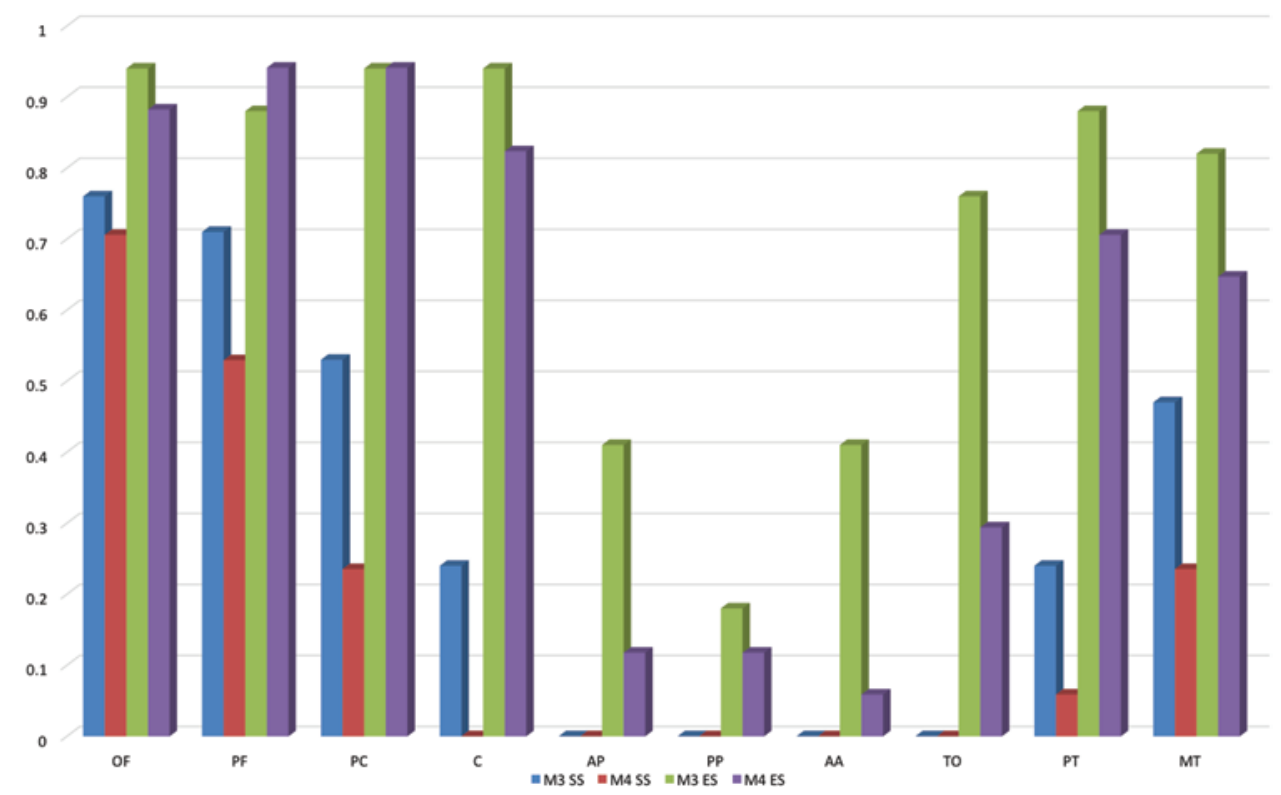

FIG. 4. Graph depicting the relative frequency of successful end-to-side and side-to-side bypasses to different $M_{3}$ and $M_{4}$ arterial territories. $\mathrm{C}$ = central artery; $\mathrm{ES}=$ end-to-side bypass; $\mathrm{SS}=$ side-to-side bypass. Figure is available in color online only.

not be appropriate for all cases. The vascular territory of the ATA can be variable and the ATA may supply some parts of the eloquent PT cortex, especially if the middle temporal (MT) and/or PT arteries are not large. Therefore, it is important to evaluate the angiography or neurovascular imaging of the individual patient to determine if the ATA is supplying the temporal cortex beyond these "safe" distances, and therefore select the patients very carefully. Furthermore, possible morbidities of an anterior temporal infarct (including visual/spatial memory deficits) and the ways to prevent/minimize those complications need to be discussed with the patient prior to using the ATA for an end-to-side bypass.

\section{Conclusions}

The ATA is a useful donor for IC-IC MCA bypass to arteries lying on the anterior insula and opercular and cortical branches on the frontal and temporal lobes. Our results also show that the ATA is a suboptimal donor for bypass to the arteries of the parietal, occipital, and PT regions. However, arterial variability exists, and ATA redundancy may extend the reach to areas further than our results suggest. Caution is required when a sizable ATA supplies eloquent parts of the PT lobe. The ATA facilitates IC-IC bypasses with MCA aneurysms and is an important donor artery when the superficial temporal artery is diminutive or unavailable for an EC-IC bypass. The results of this study may encourage neurosurgeons to use the ATA in revascularization of the MCA territory. Clinical studies could supplement the results of our study regarding surgical outcomes of ATA-MCA bypass.

\section{Acknowledgments}

We would like to express our gratitude to the body donors and their families, which, through their altruism, contributed to making this project possible. We also thank Ken Probst for the illustrations included in this article.

\section{References}

1. Abla AA, Lawton MT: Anterior cerebral artery bypass for complex aneurysms: an experience with intracranial-intracranial reconstruction and review of bypass options. J Neurosurg 120:1364-1377, 2014

2. Abla AA, McDougall CM, Breshears JD, Lawton MT: Intracranial-to-intracranial bypass for posterior inferior cerebellar artery aneurysms: options, technical challenges, and results in 35 patients. J Neurosurg 124:1275-1286, 2015

3. Bederson JB, Spetzler RF: Anastomosis of the anterior temporal artery to a secondary trunk of the middle cerebral artery for treatment of a giant M1 segment aneurysm. Case report. J Neurosurg 76:863-866, 1992

4. Behrens E, Schramm J, Zentner J, König R: Surgical and neurological complications in a series of 708 epilepsy surgery procedures. Neurosurgery 41:1-10, 1997

5. Benet A, Rincon-Torroella J, Lawton MT, González Sánchez JJ: Novel embalming solution for neurosurgical simulation in cadavers. J Neurosurg 120:1229-1237, 2014

6. Ciszek B, Aleksandrowicz R, Zabek M, Mazurowski W: Classification, topography and morphometry of the early branches of the middle cerebral artery. Folia Morphol (Warsz) 55:229-230, 1996

7. Dashti R, Hernesniemi J, Niemelä M, Rinne J, Lehecka M, Shen H, et al: Microneurosurgical management of distal middle cerebral artery aneurysms. Surg Neurol 67:553-563, 2007

8. Davies KG, Weeks RD: Temporal lobectomy for intractable epilepsy: experience with 58 cases over 21 years. Br J Neurosurg 7:23-33, 1993

9. De Long WB: Anatomy of the middle cerebral artery: the temporal branches. Stroke 4:412-418, 1973

10. Gibo H, Carver CC, Rhoton AL Jr, Lenkey C, Mitchell RJ: Microsurgical anatomy of the middle cerebral artery. J Neurosurg 54:151-169, 1981

11. González Delgado M, Bogousslavsky J: Superficial middle 
cerebral artery territory infarction. Front Neurol Neurosci 30:111-114, 2012

12. Horiuchi T, Tanaka Y, Takasawa H, Murata T, Yako T, Hongo K: Ruptured distal middle cerebral artery aneurysm. J Neurosurg 100:384-388, 2004

13. Ipekdal HI, Karadas O, Erdogan E, Gokcil Z: Spectrum of surgical complications of temporal lobe epilepsy surgery: a single-center study. Turk Neurosurg 21:147-151, 2011

14. Jafar JJ, Russell SM, Woo HH: Treatment of giant intracranial aneurysms with saphenous vein extracranial-to-intracranial bypass grafting: indications, operative technique, and results in 29 patients. Neurosurgery 51:138-146, 2002

15. Jones JE, Blocher JB, Jackson DC: Life outcomes of anterior temporal lobectomy: serial long-term follow-up evaluations. Neurosurgery 73:1018-1025, 2013

16. Joo SP, Kim TS, Choi JW, Lee JK, Kim YS, Moon KS, et al: Characteristics and management of ruptured distal middle cerebral artery aneurysms. Acta Neurochir (Wien) 149:661-667, 2007

17. Jung JM, Oh CW, Song KS, Bang JS: Emergency in situ bypass during middle cerebral artery aneurysm surgery: middle cerebral artery-superficial temporal artery interposition graft-middle cerebral artery anastomosis. J Korean Neurosurg Soc 51:292-295, 2012

18. Kalani MY, Ramey W, Albuquerque FC, McDougall CG, Nakaji P, Zabramski JM, et al: Revascularization and aneurysm surgery: techniques, indications, and outcomes in the endovascular era. Neurosurgery 74:482-498, 2014

19. Kawashima M, Rhoton AL Jr, Tanriover N, Ulm AJ, Yasuda A, Fujii K: Microsurgical anatomy of cerebral revascularization. Part I: anterior circulation. J Neurosurg 102:116-131, 2005

20. Kivipelto L, Niemelä M, Meling T, Lehecka M, Lehto H, Hernesniemi J: Bypass surgery for complex middle cerebral artery aneurysms: impact of the exact location in the MCA tree. J Neurosurg 120:398-408, 2014

21. McClelland S III, Guo H, Okuyemi KS: Population-based analysis of morbidity and mortality following surgery for intractable temporal lobe epilepsy in the United States. Arch Neurol 68:725-729, 2011

22. Mrak G, Paladino J, Stambolija V, Nemir J, Sekhar LN: Treatment of giant and large fusiform middle cerebral artery aneurysms with excision and interposition radial artery graft in a 4-year-old child: case report. Neurosurgery 10 (Suppl 1):E172-E177, 2014

23. Nussbaum ES, Madison MT, Goddard JK, Lassig JP, Nussbaum LA: Peripheral intracranial aneurysms: management challenges in 60 consecutive cases. J Neurosurg 110:7-13, 2009

24. Phuong LK, Link M, Wijdicks E: Management of intracranial infectious aneurysms: a series of 16 cases. Neurosurgery 51:1145-1152, 2002

25. Popovic EA, Fabinyi GC, Brazenor GA, Berkovic SF, Bladin PF: Temporal lobectomy for epilepsy-complications in 200 patients. J Clin Neurosci 2:238-244, 1995

26. Quiñones-Hinojosa A, Lawton MT: In situ bypass in the management of complex intracranial aneurysms: technique application in 13 patients. Neurosurgery 57 (1 Suppl): $140-145,2005$

27. Ramanathan D, Hegazy A, Mukherjee SK, Sekhar LN: Intracranial in situ side-to-side microvascular anastomosis: principles, operative technique, and applications. World Neurosurg 73:317-325, 2010
28. Rinne J, Hernesniemi J, Niskanen M, Vapalahti M: Analysis of 561 patients with 690 middle cerebral artery aneurysms: anatomic and clinical features as correlated to management outcome. Neurosurgery 38:2-11, 1996

29. Rodríguez-Hernández A, Sughrue ME, Akhavan S, Habdank-Kolaczkowski J, Lawton MT: Current management of middle cerebral artery aneurysms: surgical results with a "clip first" policy. Neurosurgery 72:415-427, 2013

30. Rodríguez-Hernández A, Zador Z, Rodríguez-Mena R, Lawton MT: Distal aneurysms of intracranial arteries: application of numerical nomenclature, predilection for cerebellar arteries, and results of surgical management. World Neurosurg 80:103-112, 2013

31. Sanai N, Zador Z, Lawton MT: Bypass surgery for complex brain aneurysms: an assessment of intracranial-intracranial bypass. Neurosurgery 65:670-683, 2009

32. Sindou M, Guenot M, Isnard J, Ryvlin P, Fischer C, Mauguière F: Temporo-mesial epilepsy surgery: outcome and complications in 100 consecutive adult patients. Acta Neurochir (Wien) 148:39-45, 2006

33. Tanriover N, Kawashima M, Rhoton AL Jr, Ulm AJ, Mericle RA: Microsurgical anatomy of the early branches of the middle cerebral artery: morphometric analysis and classification with angiographic correlation. J Neurosurg 98:1277-1290, 2003

34. Tanriover N, Rhoton AL Jr, Kawashima M, Ulm AJ, Yasuda A: Microsurgical anatomy of the insula and the sylvian fissure. J Neurosurg 100:891-922, 2004

35. Umansky F, Juarez SM, Dujovny M, Ausman JI, Diaz FG, Gomes F, et al: Microsurgical anatomy of the proximal segments of the middle cerebral artery. J Neurosurg 61:458467,1984

36. Waddington MM, Ring BA: Syndromes of occlusions of middle cerebral artery branches. Brain 91:685-696, 1968

37. Wyler AR: Anterior temporal lobectomy. Surg Neurol 54:341-345, 2000

38. Yaşargil M: Microneurosurgery: Clinical Considerations, Surgery of the Intracranial Aneurysms and Results. Stuttgart: Thieme, 1984, Vol II

\section{Disclosures}

The authors report no conflict of interest concerning the materials or methods used in this study or the findings specified in this paper.

\section{Author Contributions}

Conception and design: Benet, Tayebi Meybodi, Lawton. Acquisition of data: Tayebi Meybodi, Griswold, Mokhtari, Payman. Analysis and interpretation of data: Tayebi Meybodi, Griswold. Drafting the article: Benet, Tayebi Meybodi. Critically revising the article: all authors. Reviewed submitted version of manuscript: Benet, Tayebi Meybodi. Approved the final version of the manuscript on behalf of all authors: Benet. Statistical analysis: Griswold. Administrative/technical/material support: Benet, Lawton. Study supervision: Benet, Lawton.

\section{Correspondence}

Arnau Benet, Department of Neurosurgery, Rm. M-779, University of California, San Francisco, 505 Parnassus Ave., San Francisco, CA 94143. email: arnau.benet@ucsf.edu. 